\title{
Wafer-Scale Single-Crystal Monolayer Graphene Grown Directly on Insulating Substrates
}

Junzhu Li

King Abdullah University of Science and Technology

\section{Mingguang Chen}

Physical Science and Engineering Division, King Abdullah University of Science and Technology, Thuwal 23955-6900, Saudi Arabia.

\section{Abdus Samad}

King Abdullah University of Science and Technology

\section{Haocong Dong}

Eleven-dimensional Nanomaterial Research Institute

\section{Avijeet Ray}

King Abdullah University of Science and Technology

\section{Junwei Zhang}

Key Laboratory for Magnetism and Magnetic Materials of Ministry of Education, Lanzhou University, Lanzhou 730000, People's Republic of China

\section{Xiaochuan Jiang}

Xiamen University

\section{Udo Schwingenschlogl}

King Abdullah University of Science and Technology

\section{Jari Domke}

Institute of Solid State Physics(IFK), Friedrich Schiller University Jena, Helmholtzweg 5, 7743 Jena, Germany

\section{Cailing Chen}

Physical Science and Engineering Division, King Abdullah University of Science and Technology (KAUST), Thuwal 23955-6900, Saudi Arabia

\section{Yu Han}

Physical Science and Engineering Division, King Abdullah University of Science and Technology (KAUST), Thuwal 23955-6900, Saudi Arabia

\section{Torsten Fritz}

Institute of Solid State Physics(IFK), Friedrich Schiller University Jena, Helmholtzweg 5, 7743 Jena, Germany

\section{Bo Tian ( $\nabla$ bo.tian@kaust.edu.sa )}

King Abdullah University of Science and Technology https://orcid.org/0000-0002-1575-0491

\section{Xixiang Zhang ( $\nabla$ xixiang.zhang@kaust.edu.sa )}


King Abdullah University of Science and Technology https://orcid.org/0000-0002-3478-6414

\section{Article}

Keywords: single-crystal graphene, MPE-CVD, metal catalysis

Posted Date: May 17th, 2021

DOl: https://doi.org/10.21203/rs.3.rs-95262/v1

License: (9) This work is licensed under a Creative Commons Attribution 4.0 International License. Read Full License

Version of Record: A version of this preprint was published at Nature Materials on January 20th, 2022. See the published version at https://doi.org/10.1038/s41563-021-01174-1. 


\section{Wafer-Scale Single-Crystal Monolayer Graphene Grown Directly on}

\section{Insulating Substrates}

Junzhu Li ${ }^{1,2}$, Mingguang Chen ${ }^{1}$, Abdus Samad ${ }^{1}$, Haocong Dong ${ }^{1,2}$, Avijeet Ray ${ }^{1}$, Junwei Zhang ${ }^{3}$, Xiaochuan Jiang ${ }^{2,4}$, Udo Schwingenschlögl ${ }^{1}$, Jari Domke ${ }^{5}$, Cailing Chen ${ }^{1}$, Yu Han ${ }^{1}$, Torsten

Fritz $^{5}$, Bo Tian ${ }^{1,2 *}$, Xixiang Zhang ${ }^{1 *}$

${ }^{1}$ Physical Science and Engineering Division, King Abdullah University of Science and Technology (KAUST), Thuwal 23955-6900, Saudi Arabia.

${ }^{2}$ Eleven-dimensional Nanomaterial Research Institute, Xiamen 361005, China.

${ }^{3}$ Key Laboratory of Magnetism and Magnetic Materials of Ministry of Education, Lanzhou University, Lanzhou 730000, China.

${ }^{4}$ Department of Physics, Xiamen University, Xiamen 361005, China. ${ }^{5}$ Institute of Solid State Physics (IFK), Friedrich Schiller University Jena, Helmholtzweg 5, 07743 Jena, Germany

*e-mail: bo.tian@kaust.edu.sa; xixiang.zhang@kaust.edu.sa 
Currently, the direct synthesis of inch-scale single-crystal graphene on insulating substrates is limited by the lack of metal catalysis, suitable crystallization conditions, and self-limiting growth mechanisms. In this study, we investigated the direct growth of adlayer-free ultra-flat wafer-scale single-crystal monolayer graphene on insulating substrates by the multi-cycle plasma-etching-assisted chemical vapor deposition (MPECVD) method. Firstly, an angstrom-scale growth nanochamber was created by fabricating single-crystal $\mathrm{Cu}(111)$ foils on $\mathrm{Al}_{2} \mathrm{O}_{3}(0001)$ substrates. Graphene was then directly synthesized at the interface between $\mathrm{Cu}(111)$ and $\mathrm{Al}_{2} \mathrm{O}_{3}(0001)$ by MPE-CVD. After growth, the $\mathrm{Cu}(111)$ foil was detached using a liquid-nitrogen-assisted separation method, and the ultra-high-quality single-crystal graphene film was experimentally achieved on $\mathrm{Al}_{2} \mathrm{O}_{3}(0001)$. This work breaks the bottleneck in the direct synthesis of single-crystal monolayer graphene on insulating substrates and paves the way for next-generation carbon-based atomic electronics and semiconductor nanodevices. 
As a pioneer two-dimensional (2D) nanomaterial, graphene has attracted considerable interest in the science community ${ }^{1,2}$. Owing to its remarkable physical-chemical properties, the application of graphene is expected to bring technological breakthroughs in next-generation semiconductor nanodevices ${ }^{3}$. However, due to the limitations of graphene synthesis techniques, the prospective value and theoretically predicted properties of graphene have not yet been realized. In recent years, the discovery of superconductivity in magic-angle graphene devices has renewed the interest in graphene and its numerous attractive features ${ }^{4,5}$. Chemical vapor deposition (CVD), which involves self-limiting growth mechanisms by the $\mathrm{Cu}$-catalyzed cracking of methane, is the most widely used synthetic method to grow high-quality large-scale graphene ${ }^{6}$. However, the conventional $\mathrm{Cu}$-substrate CVD-grown graphene has inevitable issues such as electron scattering at grain boundaries, wrinkles, and adlayers, that significantly affect its electronic properties, thus limiting its application ${ }^{7}$. To date, the majority of laboratory-made graphene nanodevices are still fabricated on manually exfoliated small graphene flakes because of their superior crystal quality compared with traditional CVD-grown graphene. In light of this, a synthesis method of large-area ultra-high-quality CVD-grown graphene is urgently needed to translate the ideal properties of graphene to practical applications in the scientific research and industry.

To improve the quality of CVD-grown graphene, various strategies have been explored ${ }^{8-}$ ${ }^{10}$, including the synthesis of (i) single-crystal graphene by single-nuclei preferential growth ${ }^{11}$, (ii) adlayer-free graphene by $\mathrm{Cu}$-substrate carbon-removal pretreatment ${ }^{12}$, and (iii) ultra-flat graphene by proton penetration ${ }^{13}$. These strategies resolved various problems related to conventional $\mathrm{Cu}$-substrate $\mathrm{CVD}$ growth, leading to almost perfect graphene. However, as a metallic 2D material, graphene must be transferred to insulating substrates for application in 
nanodevices, which unavoidably introduce secondary contaminations, cracks, folds, and unexpected doping ${ }^{14}$. Hence, a more straightforward strategy was proposed through the direct CVD growth of graphene on insulating substrates. Some attempts have been made such as oxygen-assisted growth ${ }^{15}$, molten-glass-substrate synthesis ${ }^{16}$, metal-substrate carbon dissolution ${ }^{17}$, carbon diffusion through $\mathrm{Cu}$ grain boundaries ${ }^{18}, \mathrm{Cu}$-vapor-assisted CVD process ${ }^{19}$, and high-temperature metal-free $\mathrm{H}_{2}$-etched assisted growth ${ }^{20}$. These methods enable the direct growth of polycrystalline graphene layers on insulating substrates. However, due to the lack of layer-controlled mechanisms, lattice-matching epitaxy conditions, relatively low speed ratio of growth/etch, and strong interaction with insulating substrates, graphene with extremely small domain sizes, poor crystal qualities, and an uncontrolled number of layers was obtained, which limited its performance in practical nanodevices. Therefore, the direct synthesis of high-quality single-crystal graphene on insulating substrates remains a critical task.

In our study, we achieved the direct growth of adlayer-free ultra-flat wafer-scale singlecrystal monolayer graphene on insulating substrates by the multi-cycle plasma-etching-assisted CVD (MPE-CVD) growth method. First, wafer-scale single-crystal $\mathrm{Cu}(111)$ foils were synthesized on $\mathrm{Al}_{2} \mathrm{O}_{3}(0001)$ from commercial polycrystalline $\mathrm{Cu}$ foils ( $25 \mu \mathrm{m}$ thick) by a longterm annealing-driven phase-transition process. An angstrom-scale-thick superlattice-potentialdistributed growth nanochamber (ASG nanochamber) was formed at the interface of the top $\mathrm{Cu}$ (111) foil and bottom $\mathrm{Al}_{2} \mathrm{O}_{3}(0001)$ substrate. In this $\mathrm{ASG}$ nanochamber, the ultra-high-quality single-crystal graphene film was synthesized through MPE-CVD growth. The $\mathrm{Cu}(111)$ foil was easily detached after the growth process by a liquid-nitrogen-assisted extreme-temperaturedifference separation method. 


\section{Preparation of large-scale single-crystal $\mathrm{Cu}(111)$ on $\mathrm{Al}_{2} \mathrm{O}_{3}(0001)$}

The structures and properties of the substrates significantly affect the crystal orientation and domain symmetry of as-grown 2D materials; therefore, significant effort has been devoted to modifying substrates ${ }^{21,22}$. $\mathrm{Cu}(111)$ is considered as an ideal substrate for the synthesis of singlecrystal 2D materials with triangular and hexagonal symmetries such as h-BN $\left(C_{3} \mathrm{v}\right)$ and graphene $\left(C_{6 \mathrm{~V}}\right)^{23,24}$. Hence, the fabrication of large-scale single-crystal $\mathrm{Cu}$ foils is the key for the synthesis of high-quality wafer-scale 2D materials. In a previous study, the single-crystal $\mathrm{Cu}(111)$ foil was fabricated via contact-free annealing ${ }^{25}$. Inspired by this work, we produced 2-inch single-crystal $\mathrm{Cu}$ (111) foils on $\mathrm{Al}_{2} \mathrm{O}_{3}(0001)$ substrates from commercial polycrystalline $\mathrm{Cu}$ foils by long-term near-melting-temperature annealing under a hydrogen-argon atmosphere, taking advantage of lattice matching and crystal symmetry $\left(C_{6 \mathrm{~V}}\right)$.

First, the as-received polycrystalline $\mathrm{Cu}$ foil was electrochemically polished and laminated atop an $\mathrm{O}_{2}$-plasma-treated $\mathrm{Al}_{2} \mathrm{O}_{3}(0001)$ substrate, forming a $\mathrm{Cu} / \mathrm{Al}_{2} \mathrm{O}_{3}$ heterostructure, which was then placed in a CVD system for long-term high-temperature annealing under specific conditions (Supplementary Fig. 1). According to the energy distribution, $\mathrm{Cu}(111)$ was the most stable crystal with the lowest steady-state energy on the $\mathrm{Al}_{2} \mathrm{O}_{3}(0001)$ substrate compared with $\mathrm{Cu}(110)$ and $\mathrm{Cu}(100)$ crystals (Fig. 1a). Therefore, during annealing, the differently oriented crystals gradually relaxed and transformed into $\mathrm{Cu}(111)$ with the lowest stacking energy and formed a single crystal to reduce the grain boundary energy (Fig. 1b). To investigate the $\mathrm{Cu}$ crystalline phase change with annealing time, a series of time-dependent experiments was conducted. The data measured for 10 samples in each experiment revealed the gradual increase in the grain size of the $\mathrm{Cu}(111)$ crystal with annealing time, eventually covering the entire 100 $\mathrm{mm}^{2} \mathrm{Al}_{2} \mathrm{O}_{3}(0001)$ substrate (Fig. 1c). To more straightforward observe the phase transformation, 
oxidization treatment was conducted on $\mathrm{Cu}$ foils owing to the change in the color of copper oxide $\left(\mathrm{CuO}_{\mathrm{x}}\right)$ depending on $\mathrm{Cu}$ crystal orientations ${ }^{26}$ (Supplementary Fig. 2). In comparison, the phase transformations were not observed on other substrates, such as quartz, $\mathrm{Al}_{2} \mathrm{O}_{3}(10-10)$, and $\mathrm{Al}_{2} \mathrm{O}_{3}(11-20)$ (Supplementary Fig. 3). Furthermore, depending on the spatial uniformity of this phase transformation, we successfully fabricated 2-inch single-crystal $\mathrm{Cu}(111)$ foils on $\mathrm{Al}_{2} \mathrm{O}_{3}(0001)$ wafers. Optical microscopic analysis showed that the produced single-crystal $\mathrm{Cu}(111)$ almost covered the entire area without any distinct grain boundaries (Fig. 1d and Supplementary Fig. 4). The crystal orientation of the fabricated $\mathrm{Cu}(111)$ foil was confirmed by inverse pole figure (IPF) maps, which did not show any contrast difference in the entire area (Fig. 1e and Supplementary Figs. 5 and 6). Furthermore, X-ray diffraction (XRD) analysis verified the crystal phase and quality of the fabricated single-crystal $\mathrm{Cu}(111)$ foils. The XRD spectra exhibited a highly consistent sharp $\mathrm{Cu}(111)$ peak with a high signal-to-noise ratio (Fig. If and Supplementary Fig. 7).

\section{Synthesis of single-crystal graphene domains on $\mathrm{Al}_{2} \mathrm{O}_{3}(0001)$ by MPE-CVD}

During long-term annealing, the $\mathrm{Cu}$ foil gradually adhered tightly to the top surface of $\mathrm{Al}_{2} \mathrm{O}_{3}(0001)$, which resulted in the formation of the ASG nanochamber in the gap between $\mathrm{Cu}(111)$ and $\mathrm{Al}_{2} \mathrm{O}_{3}(0001)$. The distance between $\mathrm{Cu}(111)$ and $\mathrm{Al}_{2} \mathrm{O}_{3}(0001)$ was measured to be approximately $2.15 \AA$ by cross-sectional high-resolution transmission electron microscopy (HRTEM) and high-angle annular dark-field scanning transmission electron microscopy (HAADFSTEM) (Fig. 1g and Supplementary Fig. 8). The extremely small thickness of the ASG nanochamber prevented the entry of methane gas from edges of the $\mathrm{Cu}(111)$ foil, thereby avoiding the formation of poor-quality fractal-shaped graphene ${ }^{27}$. This was confirmed by 
comparison in rapid CVD growth experiments (Supplementary Fig. 9). Thus, the carbon atoms could only diffuse through the $\mathrm{Cu}(111)$ crystal into the ASG nanochamber. Besides, atomic force microscopy (AFM) analysis revealed the ultra-flat bottom surface of the long-term-annealed $\mathrm{Cu}(111)$, which is significantly smoother than that of the $\mathrm{Cu}(111)$ top surface (Supplementary Fig. 10). The smooth surface decreased the nucleation density and increased the single-domain size of graphene, thereby preventing the formation of nanographene. Moreover, the strong van der Waals interaction and same hexagonal crystal lattice symmetry of $\mathrm{Cu}(111)$ and $\mathrm{Al}_{2} \mathrm{O}_{3}(0001)$ induced a uniform superlattice potential in the ASG nanochamber, which facilitated the formation of graphene domains with the same orientation (Supplementary Fig. 11). Therefore, this ASG nanochamber was considered as an ideal platform for the synthesis of single-crystal graphene film.

The annealed $\mathrm{Cu}(111) / \mathrm{Al}_{2} \mathrm{O}_{3}(0001)$ heterostructure was placed in the MPE-CVD system for graphene synthesis that proceeded in four stages according to the main mechanism (Fig. 2a, Supplementary Fig. 12, and Supplementary Video 1): (I) carbon diffusion; (II) graphene growth; (III) plasma cleaning; and (IV) $\mathrm{Cu}$ removal. In stage I, the decomposed active carbon atoms partially condensed to graphene on the top surface of $\mathrm{Cu}(111)$ foil. Simultaneously, due to the small solubility of carbon inside the $\mathrm{Cu}(111)$ foil ${ }^{28-30}$, some carbon atoms dissolved into the $\mathrm{Cu}(111)$ crystal to form $\mathrm{Cu}-\mathrm{C}$ alloys, and slowly diffused through the foil into the ASG nanochamber to act as the carbon source for the graphene growth. A dynamic secondary ion mass spectrometry (D-SIMS) depth profiling was used to study the dissolved carbon content in the $\mathrm{Cu}$ foils of annealing and growth processes (Supplementary Fig. 13). However, no strict time limit existed between stages I and II, which were only distinguished to highlight the difference in the main mechanism of each stage. In stage II, the diffused carbon atoms initiated nucleation and 
formed graphene in the ASG nanochamber. Because of the uniform superlattice potential, graphene nuclei with the same crystal orientation were formed, which led to the formation of aligned graphene domains. Besides, the long-term hydrogen-annealing pretreatment almost completely removed carbon species in $\mathrm{Cu}(111)$ foils, which plays an essential role in the nucleation of adlayers ${ }^{12}$, leading to the growth of truly monolayer graphene. However, the topsurfaced graphene prevented carbon diffusion and decreased the catalytic efficiency during growth. Therefore, in stage III, the graphene on the top surface was removed by a hydrogenargon plasma (Supplementary Fig. 14). During the plasma cleaning process, the graphene in the ASG nanochamber remained undamaged owing to the plasma-shielding effect of the $\mathrm{Cu}$ foil ${ }^{31}$. However, considering that the non-plasma-form hydrogen can diffuse into the nanochamber and etch graphene under high temperature, the system was rapidly cooled to $300{ }^{\circ} \mathrm{C}$. During the cooling process, the $\mathrm{Cu}(111)$ foil shrank due to the considerable thermal expansion coefficient. This gradually weakened the interaction of the graphene with $\mathrm{Cu}(111)$ under the strong coupling and support of the thermally stable $\mathrm{Al}_{2} \mathrm{O}_{3}(0001)$ substrate, preventing wrinkle formation. After stage III, the sample was quickly re-heated within seconds to the stage I of the next cycle that prevented the $\mathrm{H}_{2}$ etching on as-grown graphene in the ASG nanochamber during the re-heating process. Repetition of stages I to III (multiple cycles) yielded adlayer-free ultra-flat single-crystal graphene in the ASG nanochamber. In stage IV, after the complete growth, the $\mathrm{Cu}$ foil was directly removed without any chemical contaminations by a designed liquid-nitrogen-assisted extreme-temperature-difference separation method (Supplementary Fig. 15).

After ten cycles of MPE-CVD growth, single-crystal graphene domains were directly synthesized in the ASG nanochamber (Supplementary Figs. 16 and 17). The hexagonal shape and sharp edges of aligned graphene domains indicate the high quality of the as-grown graphene 
(Fig. $2 \mathrm{~b}$ and Supplementary Fig. 18). A uniform Raman map of the $\mathrm{I}_{\mathrm{D}} / \mathrm{I}_{\mathrm{G}}$ ratio indicates that the defects in graphene are nearly non-existent (Fig. 2c), except the weak D-band Raman signal that can be observed at the domain edge area on the Raman map of D-band intensity (Supplementary Fig. 19). The full width at half maximum (FWHM) of the 2D peak in the Raman map is approximately $28 \mathrm{~cm}^{-1}$, which is typical for monolayer graphene ${ }^{32}$, thus confirming that the formed graphene does not have any adlayer (Fig. 2d). These results indicate the excellent crystal structure and high quality of the directly grown graphene. Furthermore, according to typical Raman spectra, the $2 \mathrm{D}$ peak of the graphene directly grown on $\mathrm{Al}_{2} \mathrm{O}_{3}(0001)$ was distinctly blueshifted compared with those of transferred graphene (Fig. 2e), revealing the intense coupling and strong van der Waals interaction of graphene with the $\mathrm{Al}_{2} \mathrm{O}_{3}(0001)$ substrate. The $2 \mathrm{D}$ peak of graphene grown on $\mathrm{Cu}(111)$ was more blue-shifted than that of graphene directly grown on $\mathrm{Al}_{2} \mathrm{O}_{3}(0001)$ because of the stronger interaction and stress effect between graphene and $\mathrm{Cu}(111)$ (Fig. 2f and Supplementary Fig. 20). The statistical distributions of the $2 \mathrm{D} F W H M$ and $\mathrm{I}_{2 \mathrm{D}} / \mathrm{I}_{\mathrm{G}}$ ratio reflect the high crystal quality and absence of adlayers in the graphene grown on $\mathrm{Al}_{2} \mathrm{O}_{3}(0001)$ (Fig. 2g).

\section{Growth of inch-sized single-crystal graphene film on a $\mathrm{Al}_{2} \mathrm{O}_{3}(0001)$ wafer}

We successfully synthesized wafer-scale single-crystal monolayer graphene on the substrate of $\mathrm{Al}_{2} \mathrm{O}_{3}(0001)$ by optimizing the MPE-CVD growth parameters based on the same aligned direction of crystal domains. As seen in Fig. 3a, compared to the pristine $\mathrm{Al}_{2} \mathrm{O}_{3}(0001)$ wafer, the graphene $/ \mathrm{Al}_{2} \mathrm{O}_{3}(0001)$ exhibits a weak visible-light absorption indicated by the $\mathrm{UV}-\mathrm{V}$ is transmittance spectra at a wavelength of $350-800 \mathrm{~nm}$. The single crystalline nature of the as-grown graphene film was verified by oxygen-plasma etching and chemically assisted 
grain-boundary oxidization experiments (Supplementary Fig. 21). To provide direct evidence of the single-crystalline quality of the graphene directly grown on $\mathrm{Al}_{2} \mathrm{O}_{3}$, we applied distortion corrected low energy electron diffraction (LEED) ${ }^{33-35}$. The LEED patterns obtained (Supplementary Fig. 22) were uniform over the entire measured sample area, showing a single hexagonal structure, thereby supporting the single crystalline growth of the graphene, with the graphene adopting a commensurate registry. Naturally, such a superstructure does not result in additional LEED reflexes, albeit possible multiple scattering with spot positions indistinguishable from the substrate. Therefore, we confirmed the presence of the graphene layer on the sapphire substrate by low-temperature STM, obtaining atomically resolved images of the graphene lattice from different sample areas. The fast Fourier transforms (FFTs) of the scans reveal the uniform lattice orientation including several lower intensity frequencies not corresponding to graphene that we attribute to a Moiré contrast (Supplementary Fig. 23).

Further, as determined by the Raman spectral analysis, the $\mathrm{I}_{2 \mathrm{D}} / \mathrm{I}_{\mathrm{G}}$ ratio and the $2 \mathrm{D}$ peak FWHM indicate that the directly grown wafer-scale graphene film is an adlayer-free high-quality monolayer; meanwhile, the surface roughness measured from the entire wafer area represent the ultra-flat characteristic of as-grown graphene wafer (Fig. 3b). The optical micrographs and Raman maps of the 2D peak FWHM revealed the wrinkle-free smoother surface of the graphene grown directly on $\mathrm{Al}_{2} \mathrm{O}_{3}$ compared to that of graphene grown on the upper surface of $\mathrm{Cu}$ and transferred to $\mathrm{SiO}_{2} / \mathrm{Si}$, which exhibited visible wrinkles (Fig. 3c, 3d). Based on SEM images, the graphene grown directly on $\mathrm{Al}_{2} \mathrm{O}_{3}$ has a uniform surface without any adlayer or noticeable wrinkles (Fig. 3e), whereas the $\mathrm{SiO}_{2} / \mathrm{Si}$-based transferred graphene exhibits a distinct wrinkle network (Fig. 3f). The graphene surfaces were analyzed by AFM, which revealed a smooth surface for the graphene grown directly on $\mathrm{Al}_{2} \mathrm{O}_{3}$ and rough surface with distinct wrinkles for the 
transferred graphene (Fig. 3g and Supplementary Fig. 24). HR-TEM images show the clean surface and perfect honeycomb structure of graphene grown directly on $\mathrm{Al}_{2} \mathrm{O}_{3}$ (Fig. 3h). Moreover, the crystal lattice orientations determined from the selected area electron diffraction (SAED) patterns obtained from various locations across the $3 \mathrm{~mm}$ diameter sample indicate the highly consistent single crystalline structure of the as-grown graphene.

\section{Physical mechanisms and DFT simulation}

The underlying physical mechanisms of the experimental observations were investigated by simulations based on density functional theory (DFT). Nine models were built using $\mathrm{Cu}(110)$, $\mathrm{Cu}(100), \mathrm{Cu}(111), \mathrm{Al}_{2} \mathrm{O}_{3}(11-20), \mathrm{Al}_{2} \mathrm{O}_{3}(10-10)$, and $\mathrm{Al}_{2} \mathrm{O}_{3}(0001)$ surfaces, which were analyzed in terms of crystal symmetry and lattice mismatch (Supplementary Fig. 25). The combination of $\mathrm{Cu}(111)$ and $\mathrm{Al}_{2} \mathrm{O}_{3}(0001)$ exhibited a hexagonal symmetry and the best lattice consistency with a minimal lattice mismatch of $6.5 \%$. The stacking energies per $\mathrm{Cu}$ atom were $0.98,1.33$, and 2.09 $\mathrm{eV}$ for $\mathrm{Cu}(110), \mathrm{Cu}(100)$, and $\mathrm{Cu}(111)$, respectively, indicating that $\mathrm{Cu}(111)$ is energetically favorable (Fig. 4a, 4b). The interaction between the $\mathrm{Cu}$ foil and $\mathrm{Al}_{2} \mathrm{O}_{3}$ substrate was further investigated by simulating both O-terminated and Al-terminated $\mathrm{Al}_{2} \mathrm{O}_{3}(0001)$ (Supplementary Fig. 26 and Supplementary Table 1). The higher energy states of $\mathrm{Cu}(110)$ and $\mathrm{Cu}(100)$ caused by the larger lattice mismatch resulted in gradual conversion to $\mathrm{Cu}(111)$ when the temperature approached the melting temperature.

During the MPE-CVD process, the active carbon atoms dissolved into the $\mathrm{Cu}$ foil to form a $\mathrm{Cu}-\mathrm{C}$ alloy at high temperature and gradually diffused through the foil to the $\mathrm{Cu}(111) / \mathrm{Al}_{2} \mathrm{O}_{3}(0001)$ interface ${ }^{36}$ (Fig. 4c). This carbon diffusion process was investigated by finite element simulations based on Fick's laws and convection-diffusion equations $\mathbf{s}^{37,38}$ 
(Supplementary Fig. 27). Guided by the simulation results, the experimental MPE-CVD growth process was adjusted with a specially designed temperature-variation carbon-dissolution strategy to ensure the continuous diffusion of carbon atoms. The carbon binding energies of graphene on $\mathrm{Cu}(111)$, on $\mathrm{Al}_{2} \mathrm{O}_{3}(0001)$, and at the $\mathrm{Cu}(111) / \mathrm{Al}_{2} \mathrm{O}_{3}(0001)$ interface, determined by simulations, were $0.204,0.200$, and $0.304 \mathrm{eV}$, respectively, indicating the feasibility of graphene growth at the interface (Fig. 4d). Furthermore, the binding energies of graphene on the O-terminated and Al-terminated $\mathrm{Al}_{2} \mathrm{O}_{3}(0001)$ were 0.304 and $0.081 \mathrm{eV}$ per carbon atom, respectively (Supplementary Fig. 28 and Supplementary Table 2). Because of the crystal symmetry and small lattice mismatch between $\mathrm{Cu}(111)$ and $\mathrm{Al}_{2} \mathrm{O}_{3}(0001)$, a Moiré superlattice was formed when the two materials were stacked with a twist angle (Supplementary Fig. 29), which rightfully has the matching lattice period with graphene (Fig. 4e). Under these conditions, the graphene domains grew with the same crystal orientation and subsequently merged to form a single-crystalline graphene film between $\mathrm{Cu}(111)$ and $\mathrm{Al}_{2} \mathrm{O}_{3}(0001)$.

\section{Potential applications of ultra-high-quality graphene}

The absence of an ideal synthesis method that can overcome the drawbacks of conventional CVD growth and avoid problems associated with transfer processes remains the bottleneck of the practical application of graphene in advanced carbon-based nanodevice fields. In this work, we directly grew high-quality graphene at the interface of a metal-insulator by utilizing the specifically designed ASG nanochamber formed between $\mathrm{Cu}(111)$ and $\mathrm{Al}_{2} \mathrm{O}_{3}(0001)$ through MPE-CVD growth. Owing to the pre-removal of carbon species, $\mathrm{Cu}(111)-\mathrm{Al}_{2} \mathrm{O}_{3}(0001)$ interface growth, and superlattice potential confinement, an adlayer-free ultra-flat single-crystal monolayer graphene was directly achieved on an insulating substrate. This direct growth 
technology for graphene enables the exploration of next-generation carbon-based high-

performance integrated electronics and facilitates the fulfillment of the potential of graphene in various fields. Most importantly, this work provides a new approach for the design and development of ideal epitaxial templates to grow wafer-scale single-crystal bilayer graphene or other single-crystal 2D materials (Supplementary Figs. 30 and 31), and form Moiré heterostructures thereby accelerating the research of magic angle materials on macroscale samples for fundamental research in the field of physics.

\section{Online content}

Any methods, additional references, Nature Research reporting summaries, source data, extended data, supplementary information, acknowledgements, peer review information; details of author contributions and competing interests; and statements of data and code availability are available at https://doi.org/xxxx. 


\section{References}

1 Geim, A. K. Graphene: status and prospects. Science 324, 1530-1534 (2009).

2 Novoselov, K. S. et al. A roadmap for graphene. Nature 490, 192-200 (2012).

3 Akinwande, D. et al. Graphene and two-dimensional materials for silicon technology. Nature 573, 507-518 (2019).

4 Cao, Y. et al. Correlated insulator behaviour at half-filling in magic-angle graphene superlattices. Nature 556, 80-84 (2018).

5 Cao, Y. et al. Unconventional superconductivity in magic-angle graphene superlattices. Nature 556, 43-50 (2018).

$6 \mathrm{Li}$, X. et al. Large-area synthesis of high-quality and uniform graphene films on copper foils. Science 324, 1312-1314 (2009).

7 Vlassiouk, I. V. et al. Evolutionary selection growth of two-dimensional materials on polycrystalline substrates. Nat Mater 17, 318-322 (2018).

$8 \quad$ Kim, Y. et al. Synthesis of high quality graphene on capped $\left(\begin{array}{lll}1 & 1 & 1\end{array}\right) \mathrm{Cu}$ thin films obtained by high temperature secondary grain growth on c-plane sapphire substrates. $2 D$ Materials 5, 035008 (2018).

9 Zhang, X. et al. Epitaxial growth of 6 in. single - crystalline graphene on a $\mathrm{Cu} / \mathrm{Ni}$ (111) film at $750^{\circ}$ C via chemical vapor deposition. Small 15, 1805395 (2019).

10 Huang, M. et al. Highly oriented monolayer graphene grown on a $\mathrm{Cu} / \mathrm{Ni}$ (111) alloy foil. ACS nano 12, 6117-6127 (2018).

$11 \mathrm{Wu}, \mathrm{T}$. et al. Fast growth of inch-sized single-crystalline graphene from a controlled single nucleus on Cu-Ni alloys. Nature Mater. 15, 43-47 (2016).

12 Luo, D. et al. Adlayer-Free Large-Area Single Crystal Graphene Grown on a Cu(111) Foil. Adv. Mater. 1903615, 1-13 (2019).

13 Yuan, G. et al. Proton-assisted growth of ultra-flat graphene films. Nature 577, 204-208 (2020).

14 Pirkle, A. et al. The effect of chemical residues on the physical and electrical properties of chemical vapor deposited graphene transferred to SiO2. Appl. Phys. Lett. 99, 122108 (2011).

15 Chen, J. et al. Oxygen-aided synthesis of polycrystalline graphene on silicon dioxide substrates. J. Am. Chem. Soc. 133, 17548-17551 (2011).

16 Chen, X. D. et al. Fast Growth and Broad Applications of 25-Inch Uniform Graphene Glass. Adv. Mater. 29, 1603428 (2017).

17 Pan, G. H. et al. Transfer-free growth of graphene on $\mathrm{SiO} 2$ insulator substrate from sputtered carbon and nickel films. Carbon 65, 349-358 (2013).

$18 \mathrm{Su}, \mathrm{C}$. Y. et al. Direct formation of wafer scale graphene thin layers on insulating substrates by chemical vapor deposition. Nano Lett. 11, 3612-3616 (2011).

19 Kim, H. et al. Copper-vapor-assisted chemical vapor deposition for high-quality and metal-free single-layer graphene on amorphous $\mathrm{SiO} 2$ substrate. ACS nano 7, 6575-6582 (2013).

20 Mishra, N. et al. Wafer - scale synthesis of graphene on sapphire: toward fab compatible graphene. Small 15, 1904906 (2019).

$21 \mathrm{Wu}, \mathrm{M}$. et al. Seeded growth of large single-crystal copper foils with high-index facets. Nature 581, 406-410 (2020).

22 Meiners, T., Frolov, T., Rudd, R. E., Dehm, G. \& Liebscher, C. H. Observations of grainboundary phase transformations in an elemental metal. Nature 579, 375-378 (2020). 


\begin{tabular}{|c|c|}
\hline 23 & $\begin{array}{l}\text { Li, B. W. et al. Orientation-Dependent Strain Relaxation and Chemical Functionalization } \\
\text { of Graphene on a } \mathrm{Cu}(111) \text { Foil. Adv. Mater. 30, } 1706504 \text { (2018). }\end{array}$ \\
\hline 24 & $\begin{array}{l}\text { Chen, T. A. et al. Wafer-scale single-crystal hexagonal boron nitride monolayers on } \mathrm{Cu} \\
\text { (111). Nature 579, 219-223 (2020). }\end{array}$ \\
\hline 25 & $\begin{array}{l}\text { Jin, S. et al. Colossal grain growth yields single-crystal metal foils by contact-free } \\
\text { annealing. Science } \mathbf{3 6 2}, 1021-1025 \text { (2018). }\end{array}$ \\
\hline 26 & $\begin{array}{l}\text { Constable, F. H. The cause of the colours shown during the oxidation of metallic copper. } \\
\text { Proc. R. Soc. London, Ser. A 115, 570-588 (1927). }\end{array}$ \\
\hline 27 & $\begin{array}{l}\text { Li, J. et al. Fractal-Theory-Based Control of the Shape and Quality of CVD-Grown 2D } \\
\text { Materials. Adv. Mater. 1902431, 1-7 (2019). }\end{array}$ \\
\hline 28 & $\begin{array}{l}\text { Wu, T. et al. Fast growth of inch-sized single-crystalline graphene from a controlled } \\
\text { single nucleus on } \mathrm{Cu}-\mathrm{Ni} \text { alloys. Nature Mater. 15, 43-47 (2016). }\end{array}$ \\
\hline 29 & $\begin{array}{l}\text { Zhao, Z. et al. Study on the diffusion mechanism of graphene grown on copper pockets. } \\
\text { Small 11, 1418-1422 (2015). }\end{array}$ \\
\hline 30 & $\begin{array}{l}\text { Fuks, D. et al. Carbon in copper and silver: Diffusion and mechanical properties. Journal } \\
\text { of Molecular Structure: THEOCHEM 539, 199-214 (2001). }\end{array}$ \\
\hline 31 & $\begin{array}{l}\text { Morgan, W. L., Whitten, B. L. \& Bardsley, J. N. Plasma shielding effects on ionic } \\
\text { recombination. Phys. Rev. Lett. 45, 2021-2024 (1980). }\end{array}$ \\
\hline 32 & $\begin{array}{l}\text { Ferrari, A. C. et al. Raman spectrum of graphene and graphene layers. Phys. Rev. Lett. } \\
\text { 97, } 187401 \text { (2006). }\end{array}$ \\
\hline 33 & 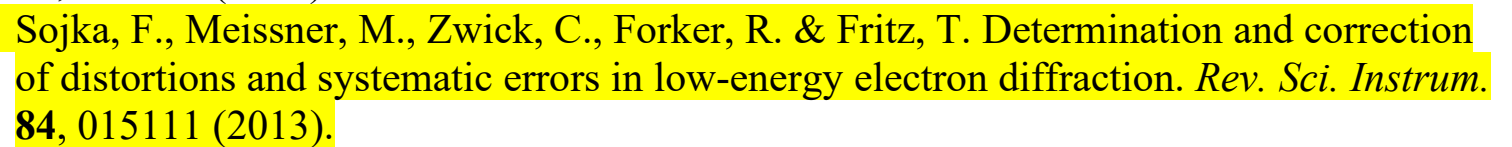 \\
\hline 34 & $\begin{array}{l}\text { Sojka, F. et al. To tilt or not to tilt: Correction of the distortion caused by inclined sample } \\
\text { surfaces in low-energy electron diffraction. Ultramicroscopy } 133,35-40 \text { (2013). }\end{array}$ \\
\hline 35 & $\begin{array}{l}\text { Schaal, M. et al. Hybridization vs decoupling: influence of an h-BN interlayer on the } \\
\text { physical properties of a lander-type molecule on Ni (111). Beilstein journal of } \\
\text { nanotechnology 11, 1168-1177 (2020). }\end{array}$ \\
\hline 36 & $\begin{array}{l}\text { Berner, A. et al. Microstructure of Cu-C interface in Cu-based metal matrix composite. } \\
\text { Sens. Actuator A Phys. 74, 86-90 (1999). }\end{array}$ \\
\hline 37 & $\begin{array}{l}\text { Kurganov, A. \& Tadmor, E. New high-resolution central schemes for nonlinear } \\
\text { conservation laws and convection-diffusion equations. J. Comput. Phys. 160, 241-282 } \\
\text { (2000). }\end{array}$ \\
\hline 38 & $\begin{array}{l}\text { Paradisi, P., Cesari, R., Mainardi, F. \& Tampieri, F. The fractional Fick's law for non- } \\
\text { local transport processes. Physica A Stat. Mech. Appl. 293, 130-142 (2001). }\end{array}$ \\
\hline
\end{tabular}

Publisher's note Springer Nature remains neutral with regard to jurisdictional claims in published maps and institutional affiliations.

(C) The Author(s), under exclusive licence to Springer Nature Limited 2020 
Preparation of single crystal $\mathrm{Cu}$ foils on $\mathrm{Al}_{2} \mathrm{O}_{3}(0001)$. The as-received polycrystalline $\mathrm{Cu}$ foil (25 $\mu \mathrm{m}$ thick, $99.9 \%$ purity from Nilaco Co.) was electrochemically polished in the polishing solution (Contents: $\mathrm{H}_{2} \mathrm{PO}_{4}$, ethanol, isopropyl alcohol, and urea), and cleaned with ethanol. The as-received $\mathrm{Al}_{2} \mathrm{O}_{3}(0001)$ substrate $(10 \mathrm{~mm} \times 10 \mathrm{~mm}$ or 2-inch, c-plane, and double-sided polished from 11-D Tech) was cleaned sequentially with acetone, isopropanol (IPA), and deionized (DI) water for 5 min in each solvent and deeply cleaned with an $\mathrm{H}_{2} \mathrm{SO}_{4}: \mathrm{H}_{3} \mathrm{PO}_{4}$ mixture $(3: 1)$ at $300{ }^{\circ} \mathrm{C}$ for $25 \mathrm{~min}$. It was cleaned again with DI water and then finally by oxygen plasma. Next, the polished $\mathrm{Cu}$ foil was flattened by a regular laminator using a protection of PET film on both sides. Then, the $\mathrm{Cu}$ foil was placed on the surface of the cleaned $\mathrm{Al}_{2} \mathrm{O}_{3}(0001)$ substrate. The $\mathrm{Cu}$ foil got attached to the surface spontaneously due to the adhesion effect. The $\mathrm{Cu} / \mathrm{Al}_{2} \mathrm{O}_{3}(0001)$ substrate was then placed in a quartz boat and inserted into a 3 -inch diameter quartz tube of the CVD system. The substrate was heated to $1350 \mathrm{~K}$ in an atmosphere of $\mathrm{H}_{2}(99.999 \%)$ and $\mathrm{Ar}(99.999 \%)$ with flow rates of 50 and $50 \mathrm{sccm}$, respectively, at a pressure of 750 torr for $24 \mathrm{~h}-30 \mathrm{~h}$. The total annealing time is slightly different and depends on the initial $\mathrm{Cu}$ foil size. During this period, the polycrystalline $\mathrm{Cu}$ foil gradually transforms into single crystal $\mathrm{Cu}(111)$. Then, the system was cooled down from $1350 \mathrm{~K}$ to $373 \mathrm{~K}$ with average cooling rates of $80 \mathrm{~K} / \mathrm{min}$ and from $373 \mathrm{~K}$ to room temperature at $10 \mathrm{~K} / \mathrm{min}$. After annealing, the $\mathrm{Cu}$ (111) foil adhered firmly to the $\mathrm{Al}_{2} \mathrm{O}_{3}(0001)$ substrate to form the $\mathrm{Cu}(111) / \mathrm{Al}_{2} \mathrm{O}_{3}(0001)$ heterostructure.

Growth of graphene via MPE-CVD. Graphene was synthesized in the ASG nanochamber between the $\mathrm{Cu}(111) / \mathrm{Al}_{2} \mathrm{O}_{3}(0001)$ heterostructure by the MPE-CVD method using mixtures of $\mathrm{CH}_{4}, \mathrm{H}_{2}$, and Ar. First, the long-term-annealed $\mathrm{Cu}(111) / \mathrm{Al}_{2} \mathrm{O}_{3}(0001)$ heterostructure was placed in the MPE-CVD system. Next, the system was heated to $1075{ }^{\circ} \mathrm{C}$ and the gases $\mathrm{H}_{2}$ and Ar were allowed to flow at a rate of 50 and $350 \mathrm{sccm}$, respectively, at a pressure of 3 torr. Then, $\mathrm{CH}_{4}$ $(99.999 \%)$ with a flow rate of $10 \mathrm{sccm}$ was purged into the tube. During this period, the carbon atoms dissolved into $\mathrm{Cu}$ and some graphene domains could start nucleation and growth on the top surface and also inside the ASG nanochamber. After $60 \mathrm{~min}$, the system was cooled to 1050 ${ }^{\circ} \mathrm{C}$ for $30 \mathrm{~min}$, to reach a conducive temperature for higher-quality graphene growth. Then, diluted $\mathrm{CH}_{4}$ gas $(0.1 \%$ diluted in Ar) with a flow rate of $10 \mathrm{sccm}$ was purged into the system to maintain a high $\mathrm{H}_{2} / \mathrm{CH}_{4}$ ratio and provide continuous carbon feeding during this period, with 10 sccm $\mathrm{H}_{2}$ and $50 \mathrm{sccm}$ Ar gas flow at 0.5 torr for $30 \mathrm{~min}$. Subsequently, the system was slowly cooled down to $300{ }^{\circ} \mathrm{C}$ in 20 min to avoid quick shrinking of the $\mathrm{Cu}$ foil. Then, the $\mathrm{CH}_{4}$ gas flow was stopped and the flow rate of $\mathrm{H}_{2}$ was increased to $30 \mathrm{sccm}$; the plasma unit $(200 \mathrm{~W})$ was moved to the sample position and switched on for 3 min to clean the graphene on the Cu upper surface. Meanwhile, the tube furnace was heated to $1075^{\circ} \mathrm{C}$ at the empty position (left side of the sample position). After plasma-etching process and waiting for the temperature of furnace to stabilize at $1075^{\circ} \mathrm{C}$, the $\mathrm{H}_{2}$ gas flow was stopped and the furnace was quickly moved back to the sample position. The sample was reheated to $1075{ }^{\circ} \mathrm{C}$ within 5 seconds, which can prevent the etching of graphene by $\mathrm{H}_{2}$ during the heating process. Then, the above processes were performed in cycle several times to obtain the final samples with single-crystal graphene in the ASG nanochamber. 


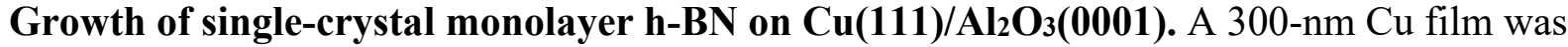
deposited on an $\mathrm{Al}_{2} \mathrm{O}_{3}(0001)$ substrate and then annealed for $1 \mathrm{~h}$ to form the $\mathrm{Cu}(111)$ film. The $\mathrm{Cu}(111) / \mathrm{Al}_{2} \mathrm{O}_{3}(0001)$ was then placed in a 3-inch CVD system. Borane-ammonia $(97 \%$, from Aldrich) was used as the precursor and loaded into a second tube. The system was heated to 1050 ${ }^{\circ} \mathrm{C}$ with 20 -sccm $\mathrm{H}_{2}$. After a 20 -min annealing process, the precursor was heated to $90{ }^{\circ} \mathrm{C}$ with 5 sccm Ar as the carrier gas. Next, the precursor was introduced into the main tube for 30 min to grow h-BN on the $\mathrm{Cu}(111) / \mathrm{Al}_{2} \mathrm{O}_{3}(0001)$ substrates. After h-BN film growth, the furnace was programmed to fast cool to $100{ }^{\circ} \mathrm{C}$ in $10 \mathrm{~min}$, and then cooled down to room temperature in 30 $\min$.

Growth of aligned h-BN domains on direct-grown graphene. Aligned h-BN domains were grown by a similar method to the growth of single-crystal monolayer h-BN on $\mathrm{Cu}(111) / \mathrm{Al}_{2} \mathrm{O}_{3}(0001)$; the difference was to replace the $\mathrm{Cu}$ foil with the as-grown single-crystal graphene $/ \mathrm{Al}_{2} \mathrm{O}_{3}(0001)$. The $\mathrm{Cu}$ foil was placed on the top of the graphene to work as the catalyst.

Growth of aligned $\mathrm{MoS}_{2}$ domains on direct-grown graphene. As-grown single-crystal graphene $/ \mathrm{Al}_{2} \mathrm{O}_{3}(0001)$ was used as a growth substrate for the synthesis of $\mathrm{MoS}_{2}$ film. $\mathrm{MoO}_{3}$ powder (99.5\%, Sigma-Aldrich) and sulfur powder (99\%, Sigma-Aldrich) were supplied as the precursor for $\mathrm{MoS}_{2}$ growth. The $\mathrm{MoO}_{3}$ powder was placed in a boat, and the single-crystal graphene $/ \mathrm{Al}_{2} \mathrm{O}_{3}(0001)$ substrate was faced down and mounted on the top of the boat. A separate boat with sulfur powder was placed next to the $\mathrm{MoO}_{3}$ powder. Then, the reaction chamber was heated to the growing temperature $\left(600-800{ }^{\circ} \mathrm{C}\right)$ at a rate of $50{ }^{\circ} \mathrm{C} \mathrm{min}{ }^{-1}$. The $\mathrm{MoS}_{2}$ domains were grown at $800{ }^{\circ} \mathrm{C}$ for $15 \mathrm{~min}$ using a carrier gas flow rate of 10 -sccm Ar. After growth, the heating furnace was quickly cooled down to room temperature.

Transfer of conventionally grown graphene onto arbitrary substrates. The conventionally grown graphene was spin-coated for 1 min by poly(methyl methacrylate) (950 PMMA C4) and then was heated at $120{ }^{\circ} \mathrm{C}$ for $20 \mathrm{~min}$. Next, the $\mathrm{Cu}$ foil was etched using a $0.03 \mathrm{~g} / \mathrm{ml}\left(\mathrm{NH}_{4}\right)_{2} \mathrm{~S}_{2} \mathrm{O}_{8}$ solution. After that, the arbitrary substrate was used to hold the PMMA/graphene and dried in air for $1 \mathrm{~h}$. Then, the samples were placed in an oven and baked at $120^{\circ} \mathrm{C}$ for $30 \mathrm{~min}$. Finally, acetone was used to remove the PMMA.

Characterization methods. Raman spectra and mapping of graphene, $h-\mathrm{BN}$, and $\mathrm{MoS}_{2}$ were obtained by confocal Raman spectroscopy (Alpha 300R, WITec) with $488 \mathrm{~nm}$ and $532 \mathrm{~nm}$ solidstate laser; $488 \mathrm{~nm}$ and $532 \mathrm{~nm}$ laser were used for the characterization of 2D materials on the $\mathrm{Cu}$ substrate and the insulating substrates, respectively. UV-Vis transmittance spectra were measured using a UV-Vis spectrophotometer (Lambda 950, PerkinElmer). Scanning electron microscopy (SEM, Merlin, Zeiss) was used to observe the morphology of graphene. The electron backscatter diffraction accessory (EBSD, Oxford Instruments) in the SEM (Quanta 600, FEI) was used to characterize the crystal phase of the $\mathrm{Cu}$ foil. The surface morphologies of $\mathrm{Cu}$ and graphene were characterized by atomic force microscopy (AFM, Dimension Icon, Bruker). X-ray diffraction (XRD, D2 PHASER, Bruker) patterns were obtained from the fabricated Cu foil. The cross-sectional TEM specimens were prepared using the focused ion beam (FIB, Helios 400S, FEI) technique. To protect the sample from ion beam damages, it was passivated using electron beam assisted Pt deposition $(300 \mathrm{~nm})$ before exposing it to the ion beam. HR-TEM imaging, 
HAADF-STEM imaging, and EDS mapping were performed on a transmission electron microscope (TEM, Titan Themis Z, FEI) equipped with a high-brightness electron gun (x-FEG), an electron beam monochromator, and a double Cs corrector operated at $300 \mathrm{kV}$. UHV-STM measurements were carried out in a low-temperature STM (SPECS Surface Nano Analysis $\mathrm{GmbH}$ ), operated at $4.5 \mathrm{~K}$ and a base pressure of $1.0 \times 10^{-10} \mathrm{Torr}$, using a tungsten tip. Low energy election diffraction (LEED) with beam diameter of approximately $1 \mathrm{~mm}$ was performed in an ultrahigh vacuum chamber with a base pressure of $1.0 \times 10^{-10}$ Torr. In order to prevent charging of the insulating substrate, a double multi-channel plate (MCP) LEED (MCP2-LEED, OCI Vacuum Microengineering) was used, and the graphene layer was contacted from the top by use of a molybdenum mask sparing a circular measurement area. Further, we applied distortion correction to the LEED images, as described in the literature ${ }^{33,34}$, by applying the software LEEDLab and LEEDCal ${ }^{35}$. Depth profiling experiments were performed on a dynamic secondary ion mass spectrometer (D-SIMS, Hiden Analytical, UK) operated under ultra-high vacuum conditions, typically $10^{-9}$ torr. A continuous $\mathrm{Ar}^{+}$beam of $4 \mathrm{keV}$ energy was employed to sputter the surface while the selected ions were sequentially collected using a MAXIM spectrometer equipped with a quadrupole analyzer.

DFT simulations. All simulations were carried out by the Vienna ab initio Simulation Package (VASP) using the projector augmented wave method and Perdew-Burke-Ernzerhof form of the generalized gradient approximation for the electron exchange-correlation potential ${ }^{39,40}$. The Grimme method was used for van der Waals correction ${ }^{41}$. A cutoff energy of $500 \mathrm{eV}$ was chosen for the plane-wave expansion. The force criterion for the structural relaxation was set to 0.001 $\mathrm{eV} / \AA$, and a $7 \times 7 \times 1 k$-mesh was used. To minimize the lattice mismatch between the components, $2 \times 2 \times 1$ supercells of $\mathrm{Cu}(111)$ and graphene were combined with a unit cell of $\mathrm{Al}_{2} \mathrm{O}_{3}(0001)$. A $14.67 \AA$ thick nine-layer slab of $\mathrm{Cu}(111)$ was used, with five layers fixed to the bulk structure and four layers free to relax. An $11.15 \AA$ thick O-terminated or $10.15 \AA$ thick Alterminated five-layer slab of $\mathrm{Al}_{2} \mathrm{O}_{3}(0001)$ was added, with three layers fixed to the bulk structure and two layers free to relax. The slab model was completed with a $20 \AA$ thick vacuum layer.

\section{Data availability}

The data that support the findings of this study are available from the corresponding author upon reasonable request.

\section{References}

39 Perdew, J. P., Burke, K. \& Ernzerhof, M. Phys rev lett 77: 3865. Phys. Rev. Lett. 78, 1396 (1996).

40 Kresse, G. Comput. matter sci. 6, 15 (1996);(d) kresse, g., and furthmuller. Phys. Rev. B 54, 11,169 (1996).

41 Grimme, S., Antony, J., Ehrlich, S. \& Krieg, H. A consistent and accurate ab initio parametrization of density functional dispersion correction (DFT-D) for the 94 elements H-Pu. J. Chem. Phys 132, 154104 (2010).

\section{Acknowledgments}

We thank R. S. Ruoff for comments on manuscript preparation. We thank Y. Gao and F. Laquai for help with UV-Vis spectrum measurement, and N. Wehbe for help with D-SIMS measurement. This work was supported by King Abdullah University of Science and 
Technology (KAUST), under award numbers: OSR-2018-CRG7-3717 and OSR-2016-CRG52996.

\section{Author contributions}

J.L. and B.T. conceived the experiments. X.Z. supervised the project. J.L. and H.D. performed the annealing of the $\mathrm{Cu}$ foils and their characterizations. J.L., M.C. and H.D. performed the graphene growth and transfer experiments. J.L., H.D. and B.T. performed the Raman, SEM, AFM, and XRD characterizations. J.Z. performed the TEM characterization for 2D materials. C.C., Y.H. and B.T. performed the FIB, HR-TEM, HAADF-STEM, and EDS characterizations for the cross-section. J.D. and T.F. performed the LEED and STM characterizations. A.S., A.R. and U.S. performed the DFT simulations. M.C., U.S., T.F. and X.Z. provided comments on the manuscript. J.L. and B.T. wrote the manuscript. All coauthors revised and commented on the manuscript.

\section{Competing interests}

The authors declare no competing interests.

16 Supplementary information is available for this paper at https://doi.org/xxx. 

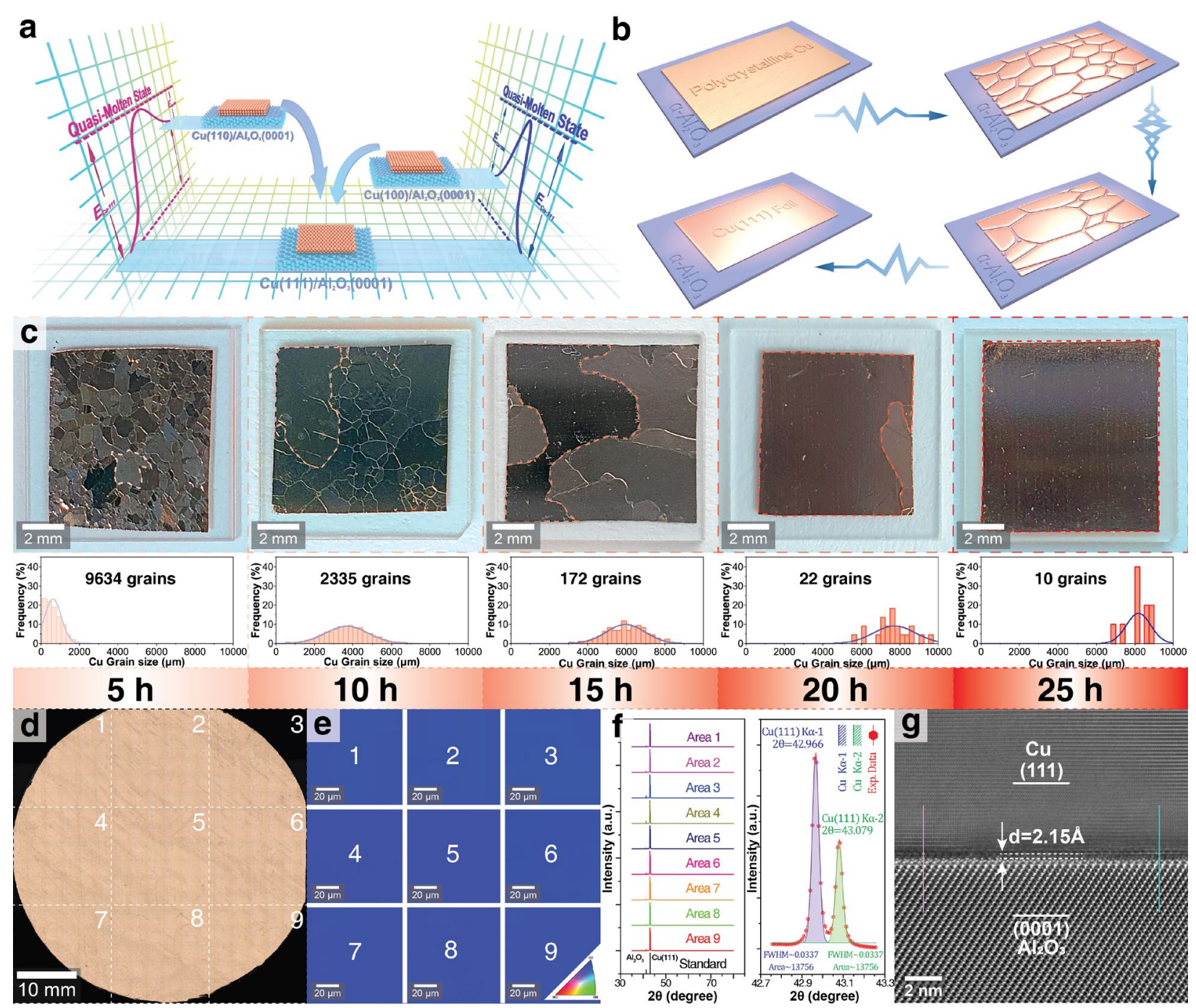

$20 \mathrm{~h}$

$25 \mathrm{~h}$
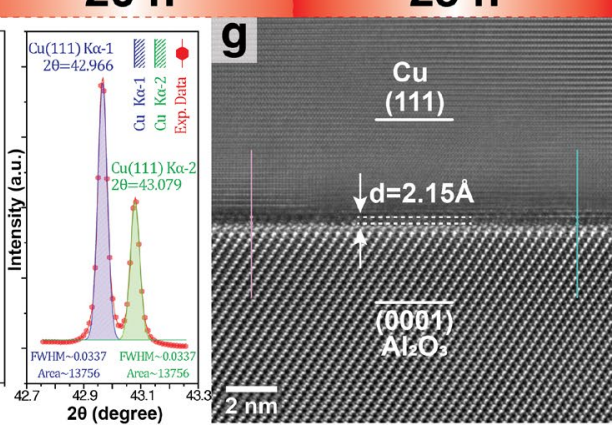

Fig. 1 | Wafer-scale single-crystal $\mathrm{Cu}(111)$ foil formed on $\mathrm{Al}_{2} \mathrm{O}_{3}(0001)$. a, Energy diagram of $\mathrm{Cu}(110), \mathrm{Cu}(100)$, and $\mathrm{Cu}(111)$ crystals on an $\mathrm{Al}_{2} \mathrm{O}_{3}(0001)$ surface. $\mathbf{b}$, Schematic of the transformation process from a commercial polycrystalline $\mathrm{Cu}$ foil into a single-crystal $\mathrm{Cu}(111)$ foil on $\mathrm{Al}_{2} \mathrm{O}_{3}(0001)$. $\mathbf{c}$, Photograph of $\mathrm{Cu}$ foil $\left(10 \times 10 \mathrm{~mm}^{2}\right)$ annealed for various periods $(5-25$ h). The largest $\mathrm{Cu}$ grain of each sample is indicated by the dashed contour. Corresponding $\mathrm{Cu}$ grain size distributions obtained by measuring 10 samples for each annealing time are also shown. d, Optical micrograph of the fabricated 2-inch single-crystal $\mathrm{Cu}(111)$ foil. The area is divided into nine parts for further characterization. e, EBSD IPF maps of the nine areas in (d). f, XRD spectra of the marked areas in (d). A distinct peak-split of the $\mathrm{Cu}(111) \mathrm{K} \alpha-1$ and $\mathrm{K} \alpha-2$ peaks is observed in the enlarged image (right) due to the ultra-high crystallinity of the fabricated $\mathrm{Cu}(111)$ foil. g, Cross-sectional HR-TEM image of the $\mathrm{Cu}(111) / \mathrm{Al}_{2} \mathrm{O}_{3}(0001)$ interface. The width of the boundary formed between $\mathrm{Cu}$ and $\mathrm{Al}_{2} \mathrm{O}_{3}$ was determined from the intensity profiles along the magenta and blue lines (see Supplementary Fig. 8 for detailed analysis). 


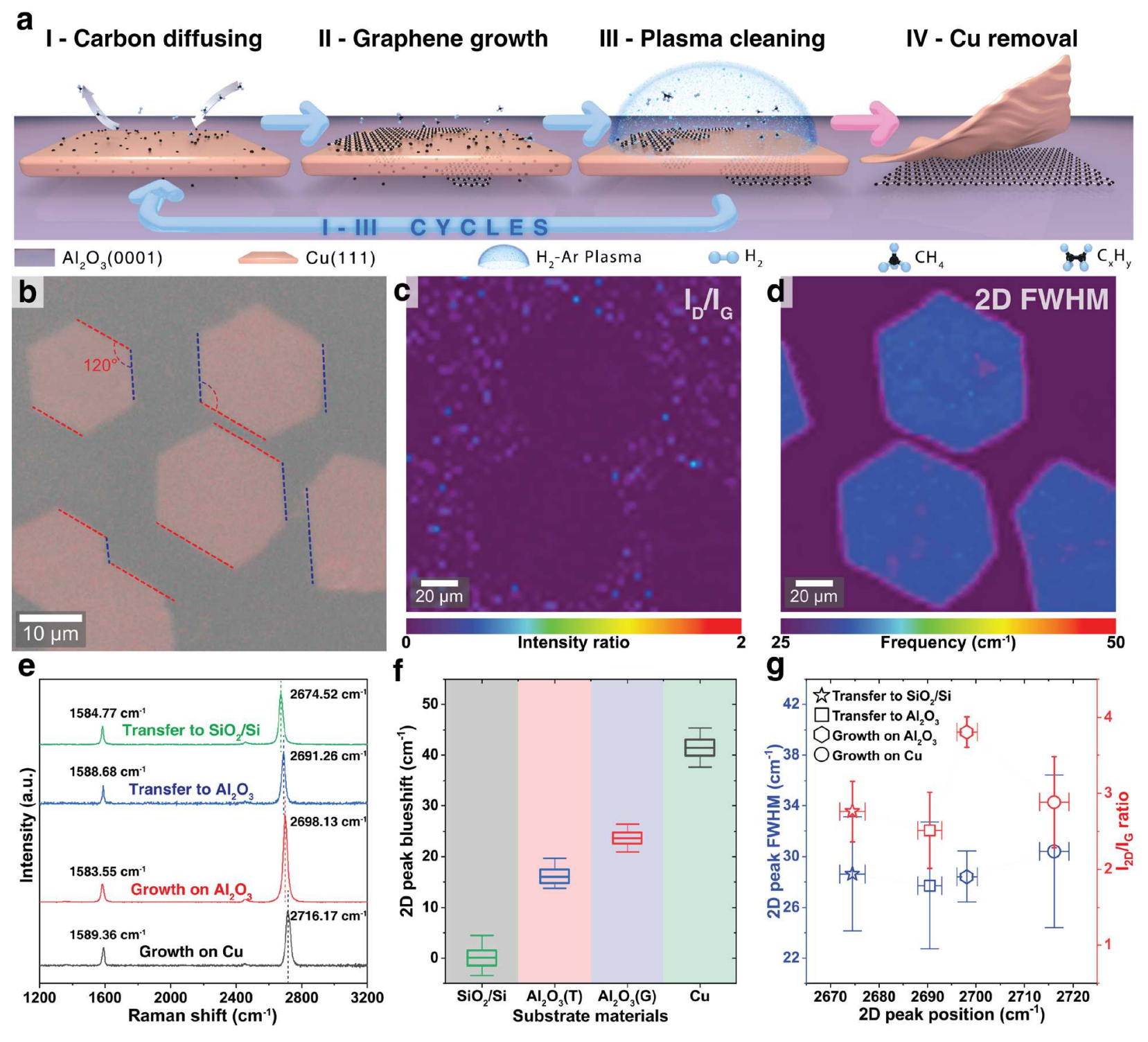

Fig. 2 | Growth of single-crystal graphene in ASG nanochamber. a, Schematic of the graphene formation process in the ASG nanochamber during MPE-CVD. b, Optical micrograph of graphene domains directly grown on $\mathrm{Al}_{2} \mathrm{O}_{3}(0001)$. The aligned orientation of individual hexagonal domains is indicated by dashed lines. c, Raman map of $\mathrm{I}_{\mathrm{D}} / \mathrm{I}_{\mathrm{G}}$ ratios of graphene crystals in the region shown in (b). d, 2D FWHM Raman map of graphene crystals in the region shown in (b). e, Representative Raman spectra of graphene grown directly on $\mathrm{Al}_{2} \mathrm{O}_{3}$ (red), graphene grown on the upper surface of $\mathrm{Cu}$ foil without transfer after removing the $\mathrm{Cu}$ fluorescence (black), graphene grown on upper surface of $\mathrm{Cu}$ foil and then transferred to $\mathrm{Al}_{2} \mathrm{O}_{3}(0001)$ (blue), and $300 \mathrm{~nm} \mathrm{SiO} / 2$ Si wafer (green). f, 2D peak blueshift of four types of graphene mentioned in (e). The 2D peak position of the $\mathrm{SiO}_{2} / \mathrm{Si}$-based transferred graphene is considered as the reference. g, 2D peak FWHM and $\mathrm{I}_{2 \mathrm{D}} / \mathrm{I}_{\mathrm{G}}$ ratio of 20 samples of each type of graphene mentioned in (e). A Raman laser with $532 \mathrm{~nm}$ wavelength is used for $\mathrm{Al}_{2} \mathrm{O}_{3}$ and $\mathrm{SiO}_{2} / \mathrm{Si}$ substrate, and $488 \mathrm{~nm}$ wavelength is used for $\mathrm{Cu}$ substrate. 

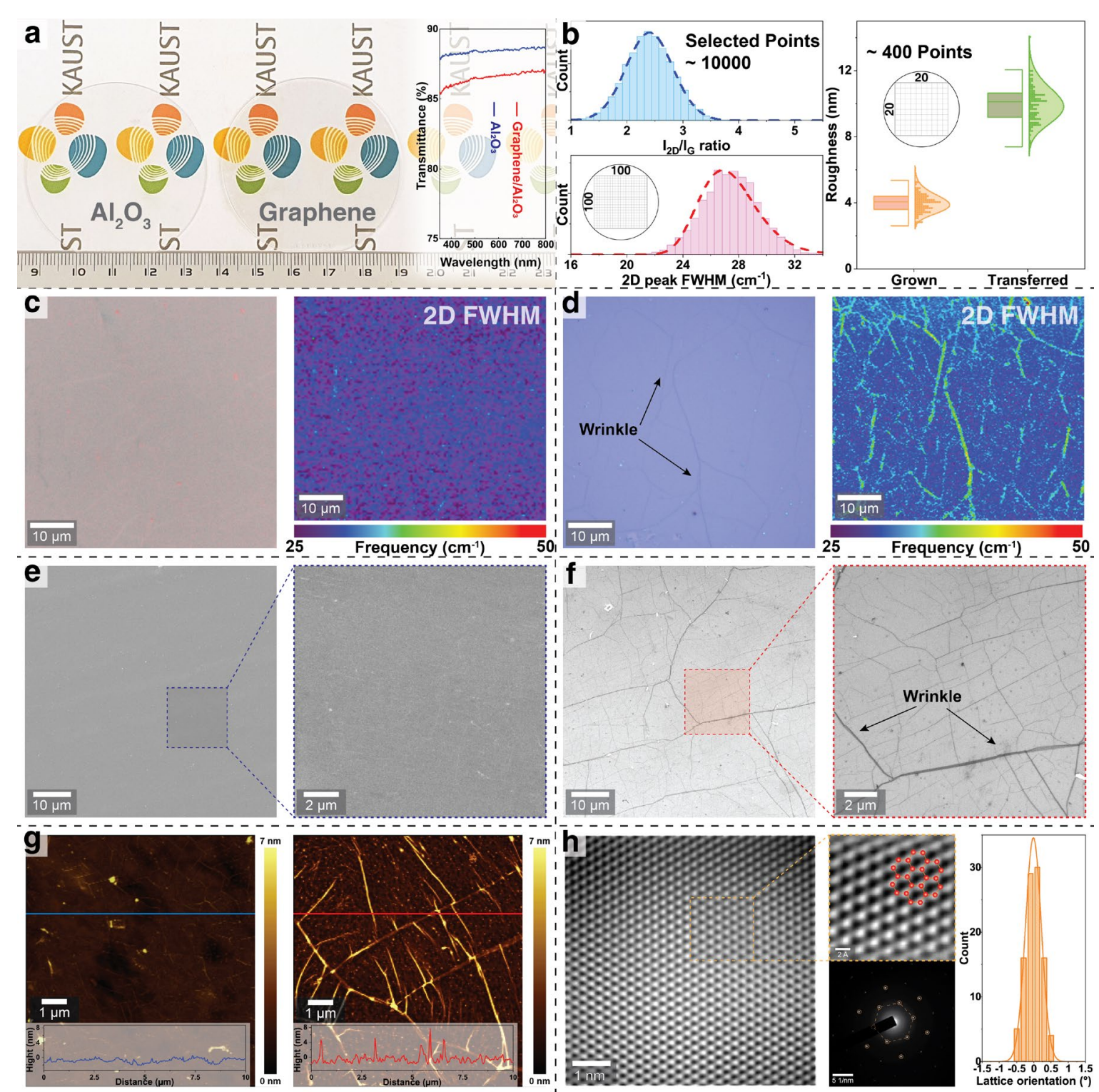

Fig. 3 | Synthesis of wafer-scale single-crystal graphene film on $\mathrm{Al}_{2} \mathrm{O}_{3}(0001)$. a, Photograph and UV-Vis transmittance spectra in the wavelength range of $350-800 \mathrm{~nm}$ of the $\mathrm{Al}_{2} \mathrm{O}_{3}(0001)$ wafer without graphene (left) and with as-grown graphene (right). b, Raman signals of $\mathrm{I}_{2 \mathrm{D}} / \mathrm{I}_{\mathrm{G}}$ intensity ratio (cyan) and 2D peak FWHM (magenta) collected from 10,000 points $(100 \times 100$ array) with $300 \mu \mathrm{m}$ step length (left); surface roughness of graphene grown directly on $\mathrm{Al}_{2} \mathrm{O}_{3}$ and graphene grown on the upper surface of $\mathrm{Cu}$ and transferred to $\mathrm{Al}_{2} \mathrm{O}_{3}$ measured by AFM with 400 pixels (20 × 20 array) (right). c, Optical image (left) and Raman map of 2D peak FWHM (right) of graphene grown directly on $\mathrm{Al}_{2} \mathrm{O}_{3}(0001)$. d, Optical image (left) and Raman map of 2D peak FWHM (right) of graphene on $\mathrm{Cu}$ and then transferred on $\mathrm{SiO}_{2} / \mathrm{Si}$ substrate. The wrinkles are indicated by the arrows. e, SEM image of graphene grown directly on $\mathrm{Al}_{2} \mathrm{O}_{3}(0001)$. f, SEM image of graphene grown on the upper surface of $\mathrm{Cu}$ and transferred to $\mathrm{SiO}_{2} / \mathrm{Si}$. g, AFM image of graphene grown directly on $\mathrm{Al}_{2} \mathrm{O}_{3}(0001)$ (left) and transferred $\mathrm{SiO}_{2} / \mathrm{Si}$-based graphene (right). The height profiles along the marked line are plotted in the bottom inset. h, High-resolution TEM image of directly grown graphene. Distribution of graphene orientation angles measured from SAED patterns at different positions over $3 \mathrm{~mm}$ diameter TEM grid. 


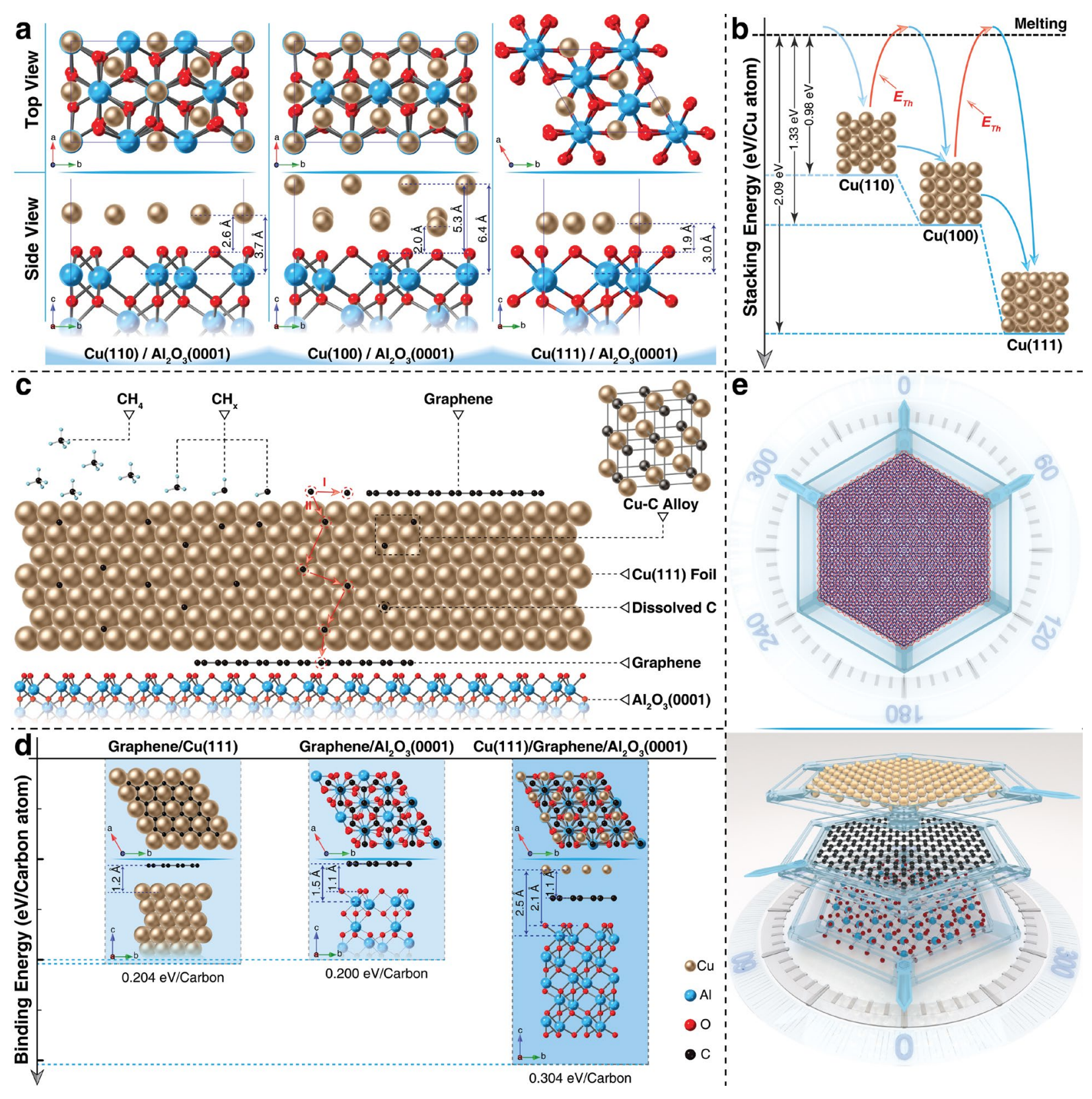

Fig. 4 | DFT simulations and carbon-diffusion model. a, Atomic structures of $\mathrm{Cu}$ on $\mathrm{Al}_{2} \mathrm{O}_{3}(0001)$ after relaxation. Top view from the $<0001>$ direction and side view from the $<11$ $20>$ direction. $\mathrm{Cu}, \mathrm{Al}$, and $\mathrm{O}$ atoms are shown in gold, blue, and red, respectively. b, Stacking energies of $\mathrm{Cu}(100), \mathrm{Cu}(110)$, and $\mathrm{Cu}(111)$ on $\mathrm{Al}_{2} \mathrm{O}_{3}(0001)$. c, Schematic of carbon diffusion through the $\mathrm{Cu}(111)$ foil and formation of a $\mathrm{Cu}-\mathrm{C}$ alloy. $\mathbf{d}$, Atomic structures and carbon binding energies for graphene on $\mathrm{Cu}(111)$, graphene on $\mathrm{Al}_{2} \mathrm{O}_{3}(0001)$, and graphene between $\mathrm{Cu}(111)$ and $\mathrm{Al}_{2} \mathrm{O}_{3}(0001)$. e, Schematic of the sandwich structure formed by $\mathrm{Cu}(111)$, graphene, and $\mathrm{Al}_{2} \mathrm{O}_{3}(0001)$, showing a Moiré superlattice pattern with $60^{\circ}$ twist angle between the layers. 


\section{Supplementary Files}

This is a list of supplementary files associated with this preprint. Click to download.

- SUPPLE1.mp4

- RevisedSupplementarylnformation.pdf 